\title{
Global impact of World Sepsis Day on digital awareness of sepsis: an evaluation using Google Trends
}

\author{
Jelmer Savelkoel ${ }^{1 *}$ (D), Theodora A. M. Claushuis², Tjitske S. R. van Engelen², Luuk J. J. Scheres ${ }^{3,4}$ \\ and W. Joost Wiersinga ${ }^{1,2^{*}}$
}

World Sepsis Day (WSD) was established by the Global Sepsis Alliance in 2012 and is held every $13^{\text {th }}$ of September. One of the objectives is to raise global awareness of sepsis. Despite its high mortality rate [1], an international survey reported that $80-90 \%$ of the public in western countries are unfamiliar with sepsis [2]. Anno 2018, public knowledge is no longer solely obtained via television and newspapers, but is largely acquired via the Internet and social media. These resources therefore contribute to digital awareness, and can be used to share knowledge. We aimed to investigate whether WSD is indeed associated with a global increase in digital informationseeking behaviour.

By using Google Trends ${ }^{\mathrm{Tw}}$ data, which are presented as the relative search volume (RSV) [3], we investigated global digital information-seeking on the terms "sepsis", "septicemia" and "blood poisoning". The methods were similar to previous work that investigated the effect of World Thrombosis Day on digital information-seeking [4]. The years 2012-2016, in which WSD was held, were considered as exposure years, with the preceding 5 years (i.e. 2007-2011) serving as control years. The period of interest was defined as the 4 weeks surrounding WSD and compared with the control period, defined as the remaining weeks of the year. Global RSV data were downloaded on the $29^{\text {th }}$ of September 2017 using the "health"

\footnotetext{
* Correspondence: j.savelkoel@amc.uva.nl; w.j.wiersinga@amc.uva.nl ${ }^{1}$ Department of Medicine and Division of Infectious Disease, Academic Medical Center, University of Amsterdam, Meibergdreef 9, Room G2-130, 1105 AZ Amsterdam, The Netherlands

Full list of author information is available at the end of the article
}

category. Data were downloaded for each year separately. Mean differences in RSV, both absolute and as percentages, between the period of interest and the control period were estimated for each year separately.

In the years that WSD was held, with the exception of the year 2012 when WSD was first introduced, we found a significant increase in digital informationseeking for the weeks surrounding WSD on terms related to sepsis compared with the remaining weeks of the year (Table 1 and Fig. 1). This was not the case for the years in which WSD was not yet held. The strengths of our approach are the focus on allencompassing terms and the ability of comparing exposure years to control years. However, we assumed

Table 1 Mean differences in relative search volume between the period of interest and the control period

\begin{tabular}{lllll}
\hline Year & $\begin{array}{l}\text { Mean RSV in } \\
\text { the } 4 \text { weeks } \\
\text { surrounding } \\
\text { WSD }\end{array}$ & $\begin{array}{l}\text { Mean RSV in the } \\
\text { remaining weeks }\end{array}$ & $\begin{array}{l}\text { Mean difference } \\
\text { in RSV }(95 \% \mathrm{Cl})\end{array}$ & $P$ value \\
\hline 2007 & 59.8 & 54.7 & & \\
2008 & 81.8 & 80.1 & $1.6(-7.0 ; 10.3)$ & 0.707 \\
2009 & 50.3 & 49.6 & $0.6(-10.0 ; 11.3)$ & 0.904 \\
2010 & 61.8 & 61.3 & $0.5(-7.8 ; 8.8)$ & 0.908 \\
2011 & 77.3 & 75.4 & $1.9(-5.4 ; 9.2)$ & 0.608 \\
2012 (WSD) & 84.0 & 72.9 & $11.1(-6.6 ; 28.7)$ & 0.142 \\
2013 (WSD) & 84.0 & 72.5 & $11.5(5.1 ; 17.9)$ & 0.001 \\
2014 (WSD) & 92.0 & 81.8 & $10.3(4.0 ; 16.5)$ & 0.002 \\
2015 (WSD) & 94.0 & 82.5 & $11.5(5.6 ; 17.3)$ & 0.000 \\
2016 (WSD) & 64.5 & 51.7 & $12.8(2.1 ; 23.6)$ & 0.021 \\
\hline
\end{tabular}

Mean difference in RSV between the period of interest (4 weeks surrounding WSD) and the control period (remaining weeks of the corresponding year) provided with the $95 \%$ confidence interval and $P$ value

$P$ values are based on the two-tailed $t$ test for computing the statistical significance. $P<0.05$ was considered significant

WSD World Sepsis Day, RSV relative search volume, $\mathrm{Cl}$ confidence interval 


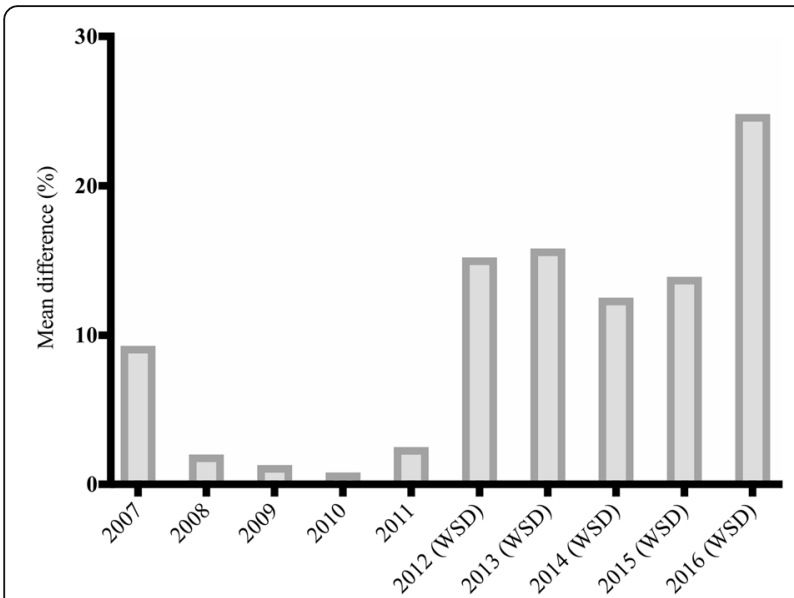

Fig. 1 Mean differences in relative search volume between the period of interest (4 weeks surrounding World Sepsis Day) and the control period (remaining weeks of the corresponding year) expressed as percentages. WSD World Sepsis Day that an increase in digital information-seeking reflects an increase in awareness on sepsis, but we do not know whether an increase in digital informationseeking equals an increase in awareness.

In conclusion, our findings suggest that WSD has an important impact on digital awareness, which could be objectified with Google Trends ${ }^{\mathrm{Tm}}$.

\section{Abbreviations}

RSV: Relative search volume; WSD: World Sepsis Day

\section{Acknowledgements}

Not applicable.

\section{Funding}

The authors have no funding to report.

\section{Availability of data and materials}

The datasets used and/or analysed during the current study are available from the corresponding author on reasonable request.

\section{Authors' contributions}

JS conceived the study, participated in its design, analysed the data and drafted the manuscript. TAMC and TSRvE participated in designing and revision of the manuscript. LJJS participated in analysing the data, and designing and revision of the manuscript. WJW participated in the design and coordination of the study, and revision of the manuscript. All authors read and approved the final manuscript.

\section{Ethics approval and consent to participate} Not applicable.

\section{Consent for publication}

Not applicable.

\section{Competing interests}

The authors declare that they have no competing interests.

\section{Publisher's Note}

Springer Nature remains neutral with regard to jurisdictional claims in published maps and institutional affiliations.

\section{Author details}

'Department of Medicine and Division of Infectious Disease, Academic Medical Center, University of Amsterdam, Meibergdreef 9, Room G2-130, 1105 AZ Amsterdam, The Netherlands. ${ }^{2}$ Center for Experimental Molecular Medicine, Academic Medical Center, University of Amsterdam, Meibergdreef 9, Room F0-117, 1105 AZ Amsterdam, The Netherlands. ${ }^{3}$ Department of Vascular Medicine, Academic Medical Center, University of Amsterdam, Meibergdreef 9, 1105 AZ Amsterdam, The Netherlands. ${ }^{4}$ Department of Clinical Epidemiology, Leiden University Medical Center, Leiden, The Netherlands.

Received: 23 January 2018 Accepted: 7 February 2018

Published online: 09 March 2018

\section{References}

1. Liu V, Escobar GJ, Greene JD, et al. Hospital deaths in patients with sepsis from 2 independent cohorts. JAMA. 2014;312:90-2.

2. Reinhart K, Kissoon NT, Daniels R, et al. What we learned from the first World Sepsis Day. J Crit Care. 2012;27:735-6.

3. Nuti SV, Wayda B, Ranasinghe I, et al. The use of google trends in health care research: a systematic review. PLoS One. 2014;9:e109583.

4. Scheres $L$, Liffering WM, Middeldorp S, et al. Influence of World Thrombosis Day on digital information seeking on venous thrombosis: a Google Trends study. J Thromb Haemost. 2016;14:2325-8. 